\title{
Microarrays as a diagnostic tool in prenatal screening strategies: ethical reflection
}

Citation for published version (APA):

de Jong, A., Dondorp, W. J., Macville, M. V. E., de Die-Smulders, C. E. M., van Lith, J. M. M., \& de Wert, G. M. W. R. (2014). Microarrays as a diagnostic tool in prenatal screening strategies: ethical reflection. Human Genetics, 133(2), 163-172. https://doi.org/10.1007/s00439-013-1365-5

Document status and date:

Published: 01/01/2014

DOI:

10.1007/s00439-013-1365-5

Document Version:

Publisher's PDF, also known as Version of record

Document license:

Taverne

Please check the document version of this publication:

- A submitted manuscript is the version of the article upon submission and before peer-review. There can be important differences between the submitted version and the official published version of record.

People interested in the research are advised to contact the author for the final version of the publication, or visit the DOI to the publisher's website.

- The final author version and the galley proof are versions of the publication after peer review.

- The final published version features the final layout of the paper including the volume, issue and page numbers.

Link to publication

\footnotetext{
General rights rights.

- You may freely distribute the URL identifying the publication in the public portal. please follow below link for the End User Agreement:

www.umlib.nl/taverne-license

Take down policy

If you believe that this document breaches copyright please contact us at:

repository@maastrichtuniversity.nl

providing details and we will investigate your claim.
}

Copyright and moral rights for the publications made accessible in the public portal are retained by the authors and/or other copyright owners and it is a condition of accessing publications that users recognise and abide by the legal requirements associated with these

- Users may download and print one copy of any publication from the public portal for the purpose of private study or research.

- You may not further distribute the material or use it for any profit-making activity or commercial gain

If the publication is distributed under the terms of Article $25 \mathrm{fa}$ of the Dutch Copyright Act, indicated by the "Taverne" license above, 


\title{
Microarrays as a diagnostic tool in prenatal screening strategies: ethical reflection
}

\author{
Antina de Jong • Wybo J. Dondorp • Merryn V. E. Macville • \\ Christine E. M. de Die-Smulders · Jan M. M. van Lith • \\ Guido M. W. R. de Wert
}

Received: 21 June 2013 / Accepted: 18 September 2013 / Published online: 28 September 2013

(C) Springer-Verlag Berlin Heidelberg 2013

\begin{abstract}
Genomic microarray analysis is increasingly being applied as a prenatal diagnostic tool. Microarrays enable searching the genome at a higher resolution and with higher sensitivity than conventional karyotyping for identifying clinically significant chromosomal abnormalities. As yet, no clear guidelines exist on whether microarrays should be applied prenatally for all indications or only in selected cases such as ultrasound abnormalities, whether a targeted or genome-wide array should be used, and what these should include exactly. In this paper, we present some ethical considerations on the prenatal use of microarrays. There is a strong consensus, at least in Western countries, that the aim of prenatal screening for foetal abnormalities should be understood as facilitating autonomous reproductive choice for prospective parents. The tests offered should be valid and useful to reach that purpose. Against this background, we address several ethical issues raised by the prenatal application of microarrays. First, we argue that
\end{abstract}

A. de Jong $(\varangle) \cdot$ W. J. Dondorp · G. M. W. R. de Wert Department of Health, Ethics and Society, Faculty of Health, Medicine and Life Sciences, Maastricht University, PO Box 616, 6200 MD Maastricht, The Netherlands

e-mail: antina.dejong@planet.nl

A. de Jong · W. J. Dondorp · C. E. M. de Die-Smulders ·

G. M. W. R. de Wert

GROW, School for Oncology and Developmental Biology,

Maastricht University, PO Box 616, 6200 MD Maastricht,

The Netherlands

A. de Jong · G. M. W. R. de Wert

CSG Centre for Society and the Life Sciences, Postvak 77, PO Box 9010, 6500 GL Nijmegen, The Netherlands

W. J. Dondorp · G. M. W. R. de Wert

CAPHRI, School for Public Health and Primary Care, Maastricht

University, PO Box 616, 6200 MD Maastricht, The Netherlands the general distinction between a targeted and a genomewide microarray needs to be scrutinised. Then we examine whether microarrays are 'suitable tests' to serve either a screening or a diagnostic purpose. Given the wide range of findings possibly generated by microarrays, the question arises whether microarrays actually promote or interfere with autonomous reproductive decision-making. Moreover, if variants of unknown clinical significance are identified, this adds to the burden and complexity of reproductive decision-making. We suggest a qualified use of microarrays in the prenatal context.

\section{Introduction}

Array-based molecular cytogenetic techniques (in short: microarrays) have for quite some time been routinely used in the postnatal setting, in particular to evaluate children

M. V. E. Macville

Clinical Laboratory, Unit Cytogenetics, Department of Clinical Genetics, Maastricht University Clinical Genetics, PO Box 5800, 6202 AZ Maastricht, The Netherlands

C. E. M. de Die-Smulders

Department of Clinical Genetics, Maastricht University Medical Center+, azM, PO Box 5800, 6202 AZ Maastricht, The Netherlands

J. M. M. van Lith

Department of Obstetrics and Fetal Medicine, Leiden University Medical Centre, P.O. Box 9600, 2300 RC Leiden,

The Netherlands 
with mental retardation or other abnormal phenotypes with unknown cause (Bejjani and Shaffer 2006; Shaffer et al. 2006; Stankiewicz and Beaudet 2007). Microarrays enable searching the entire genome for copy number variants (CNVs) at a higher resolution and with higher sensitivity than conventional karyotyping, and can detect more clinically relevant abnormalities (Armengol et al. 2012; Savage et al. 2011; Wapner et al. 2012b; Zuffardi et al. 2011). Because of this increased yield, microarrays are increasingly applied as a prenatal diagnostic tool. For the moment, microarray analysis will be performed on invasively obtained foetal material, although considerable effort is being put in methods for genome-wide diagnostics by means of non-invasive prenatal testing (NIPT) (Kitzman et al. 2012; Srinivasan et al. 2013).

So far, no clear guidelines exist if and when to use microarrays prenatally. In 2010, the International Standards for Cytogenomic Arrays (ISCA) Consortium published a consensus statement in which the evidence at that time was thought to be insufficient to allow recommendations regarding prenatal applications (Miller et al. 2010). The ISCA proposed to use traditional cytogenetic methods instead. Earlier, in 2009, the American College of Obstetrics and Gynecology (ACOG) recommended to use conventional karyotyping as the principal cytogenetic tool in prenatal diagnosis, although a targeted array that focuses on detecting chromosomal abnormalities for known genetic syndromes was proposed as an adjunct tool in case of a combination of abnormal ultrasound findings and a normal conventional karyotype (ACOG 2009; Miller et al. 2010). The Italian Society of Human Genetics (SIGU) has, in 2012, recommended a genome-wide array instead of a targeted array in this situation (Novelli et al. 2012). Some expect or recommend microarray analysis to become the 'first-tier test' for all pregnancies because of its increased yield, irrespective of the indication (Bernhardt et al. 2013; Fiorentino et al. 2013; Maya et al. 2010; Savage et al. 2011). Others are more reticent about introducing this test prenatally. This reticence is mainly due to the fact that microarrays identify CNVs that can be categorised as being likely benign, likely pathogenic or a variant of unknown clinical significance (VOUS) (Hillman et al. 2011), and that arrays generate more VOUS than karyotyping (Armengol et al. 2012; Cavalli et al. 2012; Dondorp et al. 2012). Thus, finding more clinically relevant abnormalities comes at the price of finding more VOUS: estimations of the percentage of VOUS in all prenatal samples vary from $0.3-1 \%$, depending on the population tested and the platform used (Armengol et al. 2012; Coppinger et al. 2009; Wapner et al. 2012a).

Despite the differing opinions about the prenatal application of microarrays, they are already used for several indications, and mostly applied in case of foetal abnormalities shown by foetal ultrasound scans (Hillman et al. 2012; Leung et al. 2011; Savage et al. 2011; Van den Veyver et al. 2009). Most pregnancies with ultrasound anomalies show a normal karyotype and remain without an aetiological diagnosis if only conventional karyotyping is applied. Testing by microarrays at a higher resolution and for more abnormalities is therefore supposed to be beneficial because of increased detection rates (Faas et al. 2010; Hillman et al. 2012; Leung et al. 2011; Savage et al. 2011; Van den Veyver et al. 2009; Zuffardi et al. 2011): it can provide around $6 \%$ extra diagnoses in this situation (Armengol et al. 2012; Hillman et al. 2012; Wapner et al. 2012b). Another indication to perform microarray testing is to interpret chromosome rearrangements detected by conventional karyotyping of which the clinical consequences are unsure. Microarrays allow for determining the size of the imbalance and the gene content, which may help to distinguish between pathogenic versus benign findings and to shed some light on the associated phenotype (Armengol et al. 2012; Hillman et al. 2012; Wapner et al. 2012b). Moreover, microarray testing can be offered to women with an increased risk for trisomies 21, 18 and 13, either based on risk-assessment outcomes or advanced maternal age. This will improve the overall detection rate of clinically significant chromosomal abnormalities compared to conventional karyotyping, since microarray may reveal around $1.7 \%$ more cases in this group (Maya et al. 2010; Park et al. 2010; Wapner et al. $2012 b$ ). For this same reason, it has also been proposed to offer microarray as a first-tier test to all pregnant women (Armengol et al. 2012; Fiorentino et al. 2013; Maya et al. 2010; Van den Veyver et al. 2009).

To address the question what kind of microarray testing should be offered and to whom, it is morally important to assess whether this would be done for the purpose of finding a diagnosis or for screening and whether a targeted or a genome-wide microarray is a 'suitable test' for these purposes. In this paper, we will first briefly elucidate the notion of a suitable test and show how this relates to the normative framework for medical testing (diagnosis and screening). We will then go on to scrutinise the distinction between a targeted and a genome-wide microarray, and show that these notions are in need of a conceptual clarification to allow insight into the ethical implications of both. Next, we assess whether microarrays serve a diagnostic or a screening purpose, and whether they can be seen and justified as 'suitable' tests.

\section{A suitable test}

One of the well-known Wilson and Jungner criteria for population screening is that there must be a suitable test (Wilson and Jungner 1968). This notion refers to the quality of 
a test in relation to its aim. The quality of a genetic test can be determined on different levels: analytical validity, clinical validity and clinical utility. Analytical validity is the ability of the test to accurately determine the genotype of interest. Clinical validity is the accuracy with which the test can predict a phenotype. This comprises both formal test characteristics as well as predictive value in a specific population. A diagnostic test is a test with $\sim 100 \%$ positive and negative predictive value. A screening test may have a somewhat lower score in this respect and still be suitable, if a positive result can be followed up by a test of diagnostic quality. Finally, clinical utility refers to quality in the wider sense of the ability of a genetic test to generate information that is relevant and important given the specific aim of the testing procedure (Javaher and Schmidtke 2010). Taken in this wider sense, a 'suitable test' is one that would show a positive balance of aim-related advantages and unavoidable disadvantages (drawbacks and costs) of testing.

At this level, the notion of a suitable test connects with ethical acceptability, more specifically with the conditions of 'appropriateness' and 'proportionality' (Beauchamp and Childress 2009). To be appropriate, a medical activity must lead (or contribute) to achieving a legitimate aim of medicine. With regard to genetic testing, a distinction must at this point be made between the aims of diagnosis and screening. In clinical care, the aim of testing is to clarify the medical problem with which the patient presents, to allow treatment or secondary prevention. Prenatal diagnosis (indicated either in view of a genetic risk that was known prior to conception or as diagnostic follow-up testing in a prenatal screening context) is a special case, as the aim of testing in this context is to clarify the situation to either reassure the prospective parents, or to allow them to make a decision about whether or not to continue the pregnancy to term. The aim of screening programmes generally is the early detection of disease or risk factors in persons without clinical symptoms or complaints, so as to allow timely intervention (treatment or primary prevention) expected to lead to a significant health gain on a population level. Prenatal screening, however, is a special case here. There is a strong consensus, at least in Western countries, that the aim of prenatal screening for foetal abnormalities should be understood as facilitating autonomous reproductive choice for pregnant women (and their partners), rather than to achieve a population health gain by trying to prevent the birth of children with congenital abnormalities (Health Council of the Netherlands 2008; UK NSC 2007).

Assuming that medical testing is appropriate in view of a legitimate aim, the further condition of 'proportionality' requires that any drawbacks, burdens and costs are proportional to the importance of achieving that end. For instance, a costly and burdensome test which is known beforehand only to have a limited impact on clinical management, may well be disproportional. Moreover, if there is a choice between different ways to reach the same end, the least risky, burdensome, costly, etc. alternative should in principle be chosen (this is often referred to as the condition of 'subsidiarity') (American College of Medical Quality 2011).

In addition to requiring a legitimate aim and a suitable test (in the sense just given), the ethical acceptability of medical testing requires that the person to be tested (or this person's representative) has given his or her informed consent. This presumes a professional duty to provide him or her with the information needed for making a well-considered decision, including information about the aim and nature of the procedure, but also about implications of possible outcomes for the testee and any other stakeholders.

As we will show, the implementation of microarray testing in the prenatal testing cascade challenges some of these conditions of what, from the perspective of ethical acceptability, would be a suitable test.

\section{Genome-wide versus targeted microarray: a moot distinction}

Generally, a distinction is made between a genome-wide and a targeted microarray, but the meaning of the adjectives 'genome-wide' and 'targeted' is not as clear as it may seem at first sight.

First, both kinds of tests are genome-wide in the sense that both search throughout the entire genome for possible submicroscopic deletions and duplications. A targeted microarray, however, is designed to only cover genomic regions across the genome that are known to be associated with phenotypic abnormalities: thus, it can focus on various regions throughout the whole genome and include as many or as few microdeletion and duplication syndromes as thought to be needed (Savage et al. 2011). Moreover, the density of probes in both targeted and genome-wide arrays can vary. Whereas karyotyping can only detect anomalies to a resolution of $5-10 \mathrm{Mb}$, bacterial artificial chromosomes (BAC) arrays and high-resolution oligonucleotide arrays are capable of detecting changes at a much higher resolution-up to 50-100 $\mathrm{Kb}$ (Edelmann and Hirschhorn 2009; Scott et al. 2013). Microarrays can also be designed to have a different resolution for specific parts across the genome. For example, 'critical regions' that are known for being associated with specific abnormalities, may be searched at a higher resolution (thus detecting smaller deletions and duplications), whereas the remaining regions (so-called backbone regions) are searched for deletions and duplications of a greater size only (Edelmann and Hirschhorn 2009; Savage et al. 2011; Zuffardi et al. 2011). Since every microarray is biased in the sense that its design 
is based on a decision of what size and kind of deletions and duplications are to be detected, a so-called "unbiased whole-genome array-CGH" (Veltman and de Vries 2006) does not exist. It is therefore important to know what particular design an array has (resolution for critical and backbone region).

Second, the main feature of targeted prenatal microarrays, that they only cover genomic regions known to be associated with phenotypic abnormalities, has the advantage (and purpose) to minimise the number of VOUS, to equally minimise the emotional burden and counselling difficulties associated with VOUS (ACOG 2009; Kleeman et al. 2009; Le Caignec et al. 2005; Reiff et al. 2012; Shaffer et al. 2008). Still, their design means that the 'target' is not per se related to the initial indication. The microarray is mostly used for a diagnostic purpose, namely to explain a specific unclear (mostly foetal ultrasound scan) abnormality, but a targeted array targets all known genomic regions, whatever the indication. In that regard, it clearly differs from targeted testing by molecular methods for rapid aneuploidy detection (RAD) (Faas et al. 2011): whereas the scope of RAD is explicitly limited to the few abnormalities for which the pregnant woman is found to be at increased risk, the scope of a targeted microarray is not limited to a few indication-related specific genomic regions only. We therefore conclude that 'targeted' in the prenatal context is not a clear concept, but has two different meanings. On the one hand, targeted indicates that the scope of the technique is explicitly limited to the diagnostic question, i.e. to the purpose of identifying one or only a limited number of well-described disorders indicated by a specific symptom or risk assessment. This meaning applies to the narrow RAD test. On the other hand, targeted indicates that the scope of a test is limited in that it does reveal all known clinically relevant abnormalities and does not-or at least as little as possible - generate unclear findings. In the case of prenatal microarrays, this second meaning of targeted de facto applies: although there is a specific reason to perform an array-a diagnostic indication - the design of the array itself is not specifically tailored to this indication. This is not only a terminological issue, but bears ethical relevance too. From a normative perspective, the scope of a diagnostic test should be adjusted as much as possible to the initial diagnostic question. This basic conceptual clarification is an essential part of the justification for doing that specific test (criteria of appropriateness, proportionality and subsidiarity). In the case of prenatal microarrays, this does not evidently hold.

As our analysis shows, the terms 'genome-wide' and 'targeted' are equivocal and in our view therefore not suitable for indicating the ethically relevant characteristics of the two kinds of microarrays. To avoid any confusion about what 'genome-wide' and 'targeted' in the prenatal
Table 1 Ideal types of prenatal microarray testing

\begin{tabular}{ll}
\hline Denotation & $\begin{array}{c}\text { Characteristic of test } \\
\text { Undirected }\end{array}$ \\
$\begin{array}{c}\text { The test seeks all, both clear and unclear, aberrations } \\
\text { (known and unknown CNVs) }\end{array}$ \\
Directed $\quad \begin{array}{c}\text { The test seeks all known and clear aberrations (known } \\
\text { CNVs) }\end{array}$ \\
Targeted $\quad \begin{array}{c}\text { The test only seeks the aberrations indicated by the diag- } \\
\text { nostic question }\end{array}$
\end{tabular}

context mean when indicating diagnostic tests, we propose to use the terms 'undirected' and 'directed' for describing the arrays instead. 'Undirected' arrays search the whole genome, or part(s) of it, for all CNVs, both those that are associated with a known phenotype and those of uncertain clinical significance. 'Directed' microarrays aim to provide maximum detection of all clinically significant CNVs. The term 'targeted' will be reserved for tests whose scope is attuned to the diagnostic question (see Table 1).

From this classification, it follows that an undirected microarray can never be targeted. A directed array can sometimes be understood as targeted, namely, if and insofar the diagnostic question is totally undefined, as may be the case when unclear foetal ultrasound markers are found. If the direction of the diagnostic search cannot be derived from the markers, it may be necessary to look for all known and clear aberrations (directed microarray) to enlarge the chance of finding a clarification. However, a specific ultrasound finding, for example a foetal heart defect, indicates that the diagnostic search by microarray can focus on regions associated with cardiogenetic diseases only.

\section{The use of microarrays: between prenatal diagnosis, screening and research}

The case for targeted arrays

Microarrays are increasingly used as a follow-up test in a prenatal diagnosis context. One application is to clarify chromosome rearrangements detected by conventional karyotyping. In that case, the focus and aim are rather straightforward: to give more clarity about the nature and the phenotypical consequences of a specific chromosomal abnormality. Such information is important for pregnant women to make a well-informed decision about whether to terminate or continue the pregnancy. In this situation, a targeted microarray focusing on the specific region that needs clarifying only should ideally be applied to answer the diagnostic question. An array that focuses on more regions would exceed the scope of the question and would in that sense not be appropriate, but amount to excessive testing. 
The most frequent application of microarrays in prenatal diagnosis is to clarify foetal ultrasound abnormalities, and in this situation the focus is less clear-cut. First and second trimester ultrasound scans may show major structural anomalies as well as markers that may indicate heterogeneous abnormalities and syndromes. In the latter case, as will be discussed below, a targeted array will often not be possible. However, the cause of (some) major and isolated structural abnormalities may be relatively easy to identify (de Wit et al. 2013). Whenever this is the case, it would seem that an array meant to clarify the findings need not look beyond the particular genomic region(s) associated with them.

But even in cases where it would be possible to target the design of the array itself or to target the analysis of the data obtained by an (un)directed microarray (Bejjani and Shaffer 2006; Vermeesch et al. 2007), to the best of our knowledge not a targeted but a directed or an undirected array is generally used. Directed arrays as described in the literature and as used at various institutions cover around 75-200 genomic disorders (Zuffardi et al. 2011) and most of these "known deletion and duplication syndromes would not present with any specific prenatal risk factors or characteristic ultrasound findings" (Fruhman and van den Veyver 2010). This suggests that in practice, the indication or diagnostic question does not determine the decision of what test platform to use or what analysis to perform. The same arrays are used for pre- and postnatal samples and for different indications, mainly for practical and/or financial reasons. Since directed (and targeted) arrays necessitate frequent updating to include new relevant $\mathrm{CNVs}$, some commentators insist that such arrays are simply not costeffective and impractical from a laboratory point of view (Faas et al. 2010; Vetro et al. 2012). A similar argument is made by Rehm (2013) with regard to next-generation sequencing (NGS). She remarks that "(a)lthough diseasetargeted testing is likely to remain useful for the short term, laboratories are faced with the never-ending incremental costs to develop and to validate each new disease-targeted panel, as well as to update constantly the content of existing panels as new genes are identified. This burden is causing laboratories to consider more efficient approaches than targeted testing."

However, these considerations cannot conceal that in situations where a targeted test would suffice to clarify the karyotyping or ultrasound findings, the use of wider tests marks a step from prenatal diagnosis to a wider prenatal screening paradigm, where (un)directed microarrays serve as a tool to identify any foetal abnormality detectable by microarray, rather than just answer the clinical question. The same shift is behind offering (un)directed microarrays to pregnant women at increased risk for common aneuploidies (trisomies 21, 18 and 13) (Armengol et al. 2012; Fiorentino et al. 2013).
Excessive testing is ethically problematic, as it adds to the unavoidable drawbacks of testing without a possible justification in terms of aim-related advantages for the testee(s). From a proportionality perspective, a test with such implications can hardly be suitable for prenatal diagnosis. This problem may seem to disappear with the implicit shift from prenatal diagnosis to prenatal screening, where the aim of testing for foetal abnormalities is no longer bound by an indication. If prenatal screening is aimed at providing women or couples with whatever information about the foetus they may find relevant in view of autonomous reproductive decision-making, there may seem to be no such thing as 'excessive testing'. Some have followed this path towards proposing that all pregnant women should be offered an (un)directed microarray (Fiorentino et al. 2013). However, even if it could be argued that a 'maximum yield approach' would be appropriate given the aim of prenatal screening, more is needed to speak of a suitable test, especially in view of what this would entail for the testees in terms of the balance of benefits and drawbacks ('proportionality').

The place for directed arrays

If multiple ultrasound abnormalities are found, this indicates that the pregnancy could be 'at-risk', but the question at risk for what can mostly not be answered exactly. An enlarged nuchal translucency (NT) thickening (at 1112 weeks of gestation), usually defined as $\geq 3.0-3.5 \mathrm{~mm}$, is associated with an increased risk of congenital cardiac disorders and a number of genetic and non-genetic disorders, thus giving reason for follow-up testing (Sonek 2007). The mid-trimester ultrasound scan examines overall basic foetal anatomy including, amongst other things, head, heart, abdomen, spine, limbs and extremities (Salomon et al. 2011) and is used to identify a broad range of aberrations indicating heterogeneous abnormalities and syndromes. The broad and unselective character of these ultrasound scans brings about that if foetal anomalies are found, it will not always be possible to specify the diagnostic question and, thus, also to limit the scope of the follow-up diagnostic test to specific parts of the genome.

If the aim of a directed array is to clarify unspecific ultrasound findings by identifying their possible cause, such an array would in so far be 'targeted': a directed microarray may identify $6 \%$ more clinically significant $\mathrm{CNVs}$ than conventional karyotyping would do. Indeed, it can be argued that offering an ultrasound screen involves a duty to as much as possible clarify any unclear findings to either provide reassurance to pregnant women or to allow them to make a meaningful decision about whether or not to continue the pregnancy. But even if answering to an obvious indication for follow-up testing, the use of a directed array 
in such cases blurs the distinction between diagnosis and screening: while giving a better chance of clarifying the earlier findings for the prospective parents, at the same time the test will detect any other submicroscopic chromosomal abnormalities known to be relevant for the health prospects of the future child.

In the literature, an undirected array has regularly been referred to as a "diagnostic screen" (Veltman and de Vries, 2006) or as "genome wide screening" (Faas et al. 2010; Srebniak et al. 2012). However, as our analysis suggests, this qualification also applies to the use of directed arrays, even where this approach would be appropriate (rather than excessive) follow-up testing. De facto, the use of such arrays comes down to scanning the foetal genome for any possible abnormality, related or unrelated to the ultrasound findings. As a result, prenatal microarrays have an ambiguous character, which tends to obscure their purpose as a follow-up test. This may explain why publications about prenatal microarrays do not usually specify the percentage of results that actually answers the diagnostic question raised by ultrasound abnormalities. Neither is the classical distinction made between intended and incidental findings when indicating the yield of microarrays; this distinction seems to be fading with the shift towards screening for any (known) genetic abnormality. With this implicit shift, it also becomes less obvious why one would use a directed instead of an undirected array in case of unspecific ultrasound abnormalities.

The problem with undirected arrays

Proponents of an undirected array want to optimise the identification of all possibly clinically relevant CNVs. To detect these, both known and unknown regions are included in the testing array. A directed approach is seen as disadvantageous in that it will miss yet unknown clinically important aberrations (Choy et al. 2010; Faas et al. 2010; Tyreman et al. 2009). But it is far from evident that the extra yield of an undirected array gives a better chance of clarifying unspecific ultrasound findings. In most cases, what it adds is not a more adequate diagnosis, but VOUS and the hope that through further classification and research, VOUS may be turned into meaningful findings (Shaffer et al. 2012; Wapner et al. 2012b). This entails assessing "clinical findings, literature, available databases, and gene content and size to determine whether there (is) sufficient information on which to base the prediction of phenotype and, if so, whether the phenotype (is) of sufficient clinical relevance to be reported" (Wapner et al. 2012b). In other words: if a VOUS is classified, this will to a large extent be based on estimation and subjective evaluation of its possible meaning (Alesi et al. 2013). This may explain why, next to the differences in the array design, estimations on the number of VOUS vary from around 0.4 to $12 \%$ (D'Amours et al. 2012; Shaffer et al. 2012). The conclusion must be that for lack of clinical validity, undirected microarrays are a research tool rather than an instrument of clinical care. This is also apparent from regular remarks in the literature saying that the number of VOUS will decrease as 'genome-wide' arrays will be applied more often, and more novel clinically relevant CNVs will be detected (Hillman et al. 2012; Park et al. 2011). Or, as De Wit et al. (2013) state: "To allow the discovery of new pathogenic CNVs, whole genome array platforms should be recommended in the prenatal setting (...)." From an ethical point of view, there is a clear danger here that ignoring the distinction between research and care will lead to turning pregnant women into research subjects without their knowledge and consent. As Bassem et al. (2006) have remarked, "(...)whole genome arrays are explorative by design and by purpose." They therefore want to reserve undirected arrays for research purposes only, and propose to use directed arrays in diagnostic laboratories to protect patients against possible wrong interpretations. "After all", they say, "we serve patients, not study subjects."

Why indeed burden pregnant women with VOUS if this will not lead to a better diagnosis? The implicit 'shift towards screening' provides proponents of undirected arrays with a simple argument: because any information that something may be wrong with the foetus can be relevant for the decision to continue or abort the pregnancy. For instance, according to McGillivray et al. (2012) it would be paternalistic of professionals to withhold information about VOUS, because "(a) result of uncertain significance is still information" and "(i)f it is all about choice, then, no option or information potentially relevant to a woman's choice and her decision-making processes should be withheld." They add that professionals should not be held responsible for women's decisions to terminate a pregnancy in case of unclear findings. But from an ethical point of view, this equation of a 'maximum yield approach' to microarray testing with 'facilitating autonomous reproductive choice' as the accepted aim of prenatal screening is very simple. It ignores the crucial question how generating (further) unclarities would possibly serve this purpose. The message "we have found something in your foetus, but we do not know what it means" cannot reasonably be seen as relevant and helpful for prospective parents' reproductive decision-making. Choices must be meaningful to be worthwhile. If they are not, the problem is not just that reproductive autonomy becomes an empty concept, but also that its pursuit comes at a price that is no longer proportional, given the added burdens of anxiety and stress and the possible long-term impact of a decision to terminate a wanted pregnancy for what may have been false alarm. In terms 
of the ethical framework set out earlier in this paper, the conclusion must be that undirected arrays are not a suitable test, neither for the purpose of prenatal diagnosis, nor for that of prenatal screening.

Of course, the issue of unclear test results is not new and unclear findings are difficult to completely avoid in prenatal testing. Conventional karyotyping may also generate results of which the clinical significance is unclear and even a directed microarray may incidentally reveal unclear findings. The same holds for the use of prenatal ultrasound. Analysts and clinicians are used to deal with these situations, and especially clinicians may be expected to act prudently and take into account the principle of non-maleficence when reporting test results to their patients. Still, these latter situations have to be distinguished from the scenario that unclear findings are deliberately generated-as is the case with undirected microarrays.

In our view, professionals who want to offer undirected arrays to their patients should make clear that the main purpose of doing so is research: to contribute to the steadily growing knowledge about genotype-phenotype relations, and thereby to reduce the amount of VOUS. But it may well be that in some cases individual patients would directly benefit from participating in this research, as some unclear findings may be clarified swiftly and sufficiently enough to provide them with relevant information (even though still ahead of formal proof of validity). This possibility may be a reason why well-informed patients may find it worthwhile to consent to participating in such research, while accepting that this comes at a price of being confronted with more unclear or ambiguous outcomes than would otherwise be the case. Still we think that, as part of the pre-test and consent procedure, professionals offering such 'experimental diagnosis' should make clear to the woman or the couple that 'true VOUS' will not be reported to them.

\section{Informed choice and counselling for microarray testing}

Ganesamoorthy et al. (2013) have recently suggested that "the issue of balancing the use of the highest resolution arrays to maximise detection against the drawbacks of novel or uncertain findings may best be managed by giving parents the option of high-resolution or low-resolution, targeted, prenatal analysis." We do not agree. If undirected arrays are unsuitable precisely because they undermine rather than serve autonomous decision-making by pregnant women and their partners, offering this choice in the name of that ideal is a non-starter. It seems a thin disguise for the attempt to preserve the option of using genome-wide arrays while relegating the responsibility to the patient. However, leaving the decision to the woman or the couple may well be an option where there would be a choice between a targeted and a directed array. In cases where a targeted array would be an appropriate follow-up test for karyotyping or ultrasound findings, opting for a directed array would reflect the shift from diagnosis to screening. If only the prospective parents are aware of this, there seems nothing wrong with allowing them to choose this option, assuming that a directed array can more easily be justified as a suitable test for prenatal screening purposes, than an undirected one. Allowing this choice between a targeted follow-up test and a wider screening test is similar to the individualised choice' between a targeted RAD test and karyotyping (de Jong et al. 2011b).

This still raises the question how to provide prospective parents with adequate information to facilitate them to make an informed choice whether to be tested or not, and what outcomes to receive or not. The traditional interpretation of meaningful informed consent is that testees are in the pre-test situation informed about all conditions tested for, so that they can indicate what results they want to receive or not. It is clear that in case of a microarray test, this traditional interpretation of informed consent is untenable. It is impossible to extensively inform prospective parents about all the possible findings, including their clinical consequences. To do so would probably result in such an overload of information, that parents will in fact be incapacitated to give their informed consent. Categorising findings may be the best and in fact the only feasible option in the case of microarrays (de Jong et al. 2011a).

To ensure that prospective parents' views and preferences are taken into account, pre- and post-test counselling has to satisfy more than the requirements of adequate information and non-directiveness alone. The 'interpretive model' of the professional-patient relationship as introduced by Emanuel and Emanuel (1992) seems to comply best with what is needed in this situation. This model allows for a collaboration of the professional and the pregnant woman to choose the test option that suits the woman's situation and preferences best. To reach that aim, the professional informs her about the available options and helps the woman to clarify her own wants and values, to reach the decision that best fits her.

\section{Conclusion}

Microarrays enable identifying more clinically significant abnormalities than conventional karyotyping and this is usually seen as a benefit, also in the prenatal context. Although we acknowledge the advantages of microarrays, we have also shown the drawbacks of the fact that the phenotypical consequences of many CNVs are uncertain. 
We noted a tendency to use broader arrays than would be needed for clarifying karyotyping or ultrasound outcomes and an implicit shift from a prenatal diagnosis to a prenatal screening paradigm. This causes microarrays to have an ambiguous character. A clear distinction should be made between targeted, directed and undirected microarrays. If the indication pregnant women present with is clear, diagnostic testing should be done by what we have defined as a targeted microarray, ideally focussing on regions that are associated with the specific type or category of earlier findings. If, for instance, former outcomes point to cardiac problems, a targeted array would not look for CNVs associated with neurogenetic abnormalities. If such an array is not available, or cannot be made available at a reasonable cost, or if there are other justified reasons to apply a broader microarray, a directed microarray may be a suitable test. With regard to undirected arrays, we have suggested that generating VOUS serves a research purpose and does not contribute to the aim of autonomous reproductive decision-making.

More in general, the current prenatal application of microarrays seems to be complicated by the fact that the development of this technique and the gain of knowledge about its outcomes are still in progress: the application is therefore taking place in the intermediate phase between research and implementation. As a result, decisions have still to be made about what possible findings to include in a testing array or not. In that regard, the prenatal use of microarrays may reflect a so-called 'extemporaneous'(Wilfond and Nolan 1993) translation of research into clinical care, instead of a well-balanced introduction of this technique after a profound evaluation of clinical, empirical and normative issues. With increasing knowledge, it may be possible to differentiate microarrays per diagnostic question to offer a suitable test and a clear answer to the medical question at hand.

For now, prospective parents will be confronted with the question whether they want to terminate or continue the pregnancy affected with any of the CNVs found. Since selective abortion is an emotionally and ethically charged decision, providers of prenatal tests have the obligation to carefully decide what findings they will confront prospective parents with and where the line between beneficial and maleficent provision of information will be passed. Allowing pregnant women an 'individualised choice' between a targeted follow-up test and a wider screening test (directed microarray), may be an alternative. This option is in line with the aim of prenatal screening and offers women or couples the opportunity to choose the test that best fits their individual wants and needs.

Acknowledgments This research was supported by the CSG Centre for Society and the Life Sciences, funded by The Netherlands Genomics Initiative (Project number: 70.1.061b).

\section{References}

ACOG (2009) Array comparative genomic hybridization in prenatal diagnosis. Committee Opinion Number 446. Obstet Gynecol 114:5

Alesi V, Bertoli M, Sinibaldi L, Novelli A (2013) The clinical utility and indications of chromosomal microarray analysis in prenatal diagnosis. BJOG 120:119-120

American College of Medical Quality (2011) Professional and ethical policies of the American College of Medical Quality, Policy 3. Standard of care; Policy 8. Definition and application of medical necessity. http://www.acmq.org/policies/policy8.pdf

Armengol L, Nevado J, Serra-Juhé C, Plaja A, Mediano C, GarcíaSantiago F et al (2012) Clinical utility of chromosomal microarray analysis in invasive prenatal diagnosis. Hum Genet 131:513-523

Bassem A, Bejjani B, Shaffer L (2006) Targeted array CGH. J Mol Diagn 8:537-539

Beauchamp TL, Childress JF (2009) Principles of biomedical ethics. Oxford University Press Inc, Oxford

Bejjani B, Shaffer L (2006) Application of array-based comparative genomic hybridization to clinical diagnostics. Mol Diagn $8: 528-533$

Bernhardt B, Soucier D, Hanson K, Savage M, Jackson L, Wapner R (2013) Women's experiences receiving abnormal prenatal chromosomal microarray testing results. Genet Med 15:139-145

Cavalli P, Cavallari U, Novelli A (2012) Array CGH in routine prenatal diagnosis practice. Prenat Diagn 32:708-709

Choy K, Setlur S, Lee C, Lau T (2010) The impact of human copy number variation on a new era of genetic testing. BJOG 117:391-398

Coppinger J, Alliman S, Lamb A, Torchia B, Bejjani B, Shaffer L (2009) Whole-genome microarray analysis in prenatal specimens identifies clinically significant chromosome alterations without increase in results of unclear significance compared to targeted microarray. Prenat Diagn 29:1156-1166

D'Amours G, Kibar Z, Mathonnet G, Fetni R, Tihy F, Désilets V, Nizard S, Michaud JL, Lemyre E (2012) Whole-genome array $\mathrm{CGH}$ identifies pathogenic copy number variations in fetuses with major malformations and a normal karyotype. Clin Genet 81:128-141

de Jong A, Dondorp W, Frints S, de Die-Smulders C, de Wert G (2011a) Advances in prenatal screening: the ethical dimension. Nat Rev Genet 12:657-663

de Jong A, Dondorp W, Timmermans D, van Lith J, de Wert G (2011b) Rapid aneuploidy detection or karyotyping? Ethical reflection. Eur J Hum Genet 19:1020-1025

de Wit M, Srebniak M, Govaerts L, Van Opstal D, Galjaard R, Go A (2013) The additional value of prenatal genomic array testing in fetuses with (isolated) structural ultrasound abnormalities and a normal karyotype: a systematic review of the literature. Ultrasound Obstet Gynecol. doi:101002/uog125752013

Dondorp W, Sikkema-Raddatz B, de Die-Smulders C, de Wert G (2012) Arrays in postnatal and prenatal diagnosis: an exploration of the ethics of consent. Hum Mutat 33:916-922

Edelmann L, Hirschhorn K (2009) Clinical utility of array CGH for the detection of chromosomal imbalances associated with mental retardation and multiple congenital anomalies. N Y Acad Sci 1151:157-166

Emanuel E, Emanuel L (1992) Four models of the physician-patient relationship. JAMA 267:2221-2226

Faas B, van der Burgt I, Kooper A, Pfundt R, Hehir-Kwa J, Smits A et al (2010) Identification of clinically significant, submicroscopic chromosome alterations and UPD in fetuses with ultrasound anomalies using genome-wide $250 \mathrm{k}$ SNP array analysis. J Med Genet 47:586-594 
Faas BHW, Cirigliano V, Bui T-H (2011) Rapid methods for targeted prenatal diagnosis of common chromosome aneuploidies. Sem Fet Neonat Med 16:81-87

Fiorentino F, Napoletano S, Caiazzo F, Sessa M, Bono S, Spizzichino L, Gordon A, Nuccitelli A, Rizzo G, Baldi M (2013) Chromosomal microarray analysis as a first-line test in pregnancies with a priori low risk for the detection of submicroscopic chromosomal abnormalities. Eur J Hum Genet 21:725-730

Fruhman G, van den Veyver I (2010) Applications of array comparative genomic hybridization in obstetrics. Obstet Gynecol Clin North Am 37:71-85

Ganesamoorthy D, Bruno DL, McGillivray G, Norris F, White SM, Adroub S, Amor DJ, Yeung A, Oertel R, Pertile MD, Ngo C, Arvaj AR, Walker S, Charan P, Palma-Dias R, Woodrow N, Slater HR (2013) Meeting the challenge of interpreting high-resolution single nucleotide polymorphism array data in prenatal diagnosis: does increased diagnostic power outweigh the dilemma of rare variants? BJOG 120:594-606

Health Council of the Netherlands (2008) Screening: between hope and hype. Publication no. 2008/05

Hillman S, Pretlove S, Coomarasamy A, McMullan D, Davison E, Maher E et al (2011) Additional information from array comparative genomic hybridization technology over conventional karyotyping in prenatal diagnosis: a systematic review and meta-analysis. Ultrasound Obstet Gynecol 37:6-14

Hillman S, McMullan D, Maher E, Kilby M (2012) Clinical utility of array comparative genomic hybridisation for prenatal diagnosis: a cohort study of 3171 pregnancies. BJOG 119:1281-1282

Javaher P, Schmidtke J (2010) Clinical validity and utility of genetic testing in heritable disorders. In: Kristofferson U, Schmidtke J, Cassiman J-J (eds) Quality issues in clinical genetic services. Springer, Dordrecht, pp 147-156

Kitzman JO, Snyder MW, Ventura M, Lewis AP, Qiu R, Simmons LE et al (2012) Noninvasive whole-genome sequencing of a human fetus. Sci Transl Med 4:137ra176

Kleeman L, Bianchi D, Shaffer L, Rorem E, Cowan J, Craigo S et al (2009) Use of array comparative genomic hybridization for prenatal diagnosis of fetuses with sonographic anomalies and normal metaphase karyotype. Prenat Diagn 29:1213-1217

Le Caignec C, Boceno M, Saugier-Veber P, Jacquemont S, Joubert M, David A et al (2005) Detection of genomic imbalances by array based comparative genomic hybridisation in fetuses with multiple malformations. J Med Genet 42:121-128

Leung T, Vogel I, Lau T, Hyett J, Petersen O et al (2011) Identification of submicroscopic chromosomal aberrations in fetuses with increased nuchal translucency and apparently normal karyotype. Ultrasound Obstet Gynecol 38:314-319

Maya I, Davidov B, Gershovitz L, Zalzstein Y, Taub E, Coppinger $J$ et al (2010) Diagnostic utility of array-based comparative genomic hybridization (aCGH) in a prenatal setting. Prenat Diagn 30:1131-1137

McGillivray G, Rosenfield J, McKinlay Gardner R, Dillam L (2012) Genetic counselling and ethical issues with chromosome microarray analysis in prenatal testing. Prenat Diagn 32:389-395

Miller D, Adam M, Aradhya S, Biesecker L, Brothman A, Carter N et al (2010) Consensus statement: chromosomal microarray is a first-tier clinical diagnostic test for individuals with developmental disabilities or congenital anomalies. Am J Hum Genet 14:749-764

Novelli A, Grati F, Ballarati L, Bernardini L, Bizzoco D, Camurri L et al (2012) Microarray application in prenatal diagnosis: a position statement from the cytogenetics working group of the Italian Society of Human Genetics (SIGU). Ultrasound Obstet Gynecol 39:384-388

Park J, Woo J, Shim S, Yang S, Choi Y, Yang K et al (2010) Application of a target array comparative genomic hybridization to prenatal diagnosis. BMC Med Genet 11:102
Park S-J, Jung E, Ryu R-S, Kang H, Ko J-M, Kim H et al (2011) Clinical implementation of whole-genome array $\mathrm{CGH}$ as a first-tier test in 5080 pre and postnatal cases. Mol Cytogenet 4:12

Rehm H (2013) Disease-targeted sequencing: a cornerstone in the clinic. Nat Rev Genet 14:295-300

Reiff M, Ross K, Mulchandani S, Propert K, Pyeritz R, Spinner N et al (2012) Physicians' perspectives on the uncertainties and implications of chromosomal microarray testing of children and families. Clin Genet 83:23-30

Salomon L, Alfirevic Z, Berghella V, Bilardo C, Hernandez-Andrade E, Johnsen S et al (2011) Practice guidelines for performance of the routine mid-trimester fetal ultrasound scan. Ultrasound Obstet Gynecol 37:116-126

Savage M, Mourad M, Wapner R (2011) Evolving applications of microarray analysis in prenatal diagnosis. Current Op Obstet Gynecol 23:103-108

Scott F, Murphy K, Carey L, Greville W, Mansfield N, Barahona P et al (2013) Prenatal diagnosis using combined quantitative fluorescent polymerase chain reaction and array comparative genomic hybridization analysis as a first-line test: results from over 1000 consecutive cases. Ultrasound Obstet Gynecol 41:500-507

Shaffer L, Kashork C, Saleki R, Rorem E, Sundin K, Ballif B et al (2006) Targeted genomic microarray analysis for identification of chromosome abnormalities in 1500 consecutive clinical cases. J Pediatrics 149:98-102

Shaffer LG, Coppinger J, Alliman S, Torchia BA, Theisen A, Ballif $\mathrm{BC}$ et al (2008) Comparison of microarray-based detection rates for cytogenetic abnormalities in prenatal and neonatal specimens. Prenat Diagn 28:789-795

Shaffer L, Dabell M, Fisher A, Coppinger J, Bandholz A, Ellison J et al (2012) Experience with microarray-based comparative genomic hybridization for prenatal diagnosis in over 5000 pregnancies. Prenat Diagn 32:976-985

Sonek J (2007) First trimester ultrasonography in screening and detection of fetal anomalies. Am J Med Genet C Semin Med Genet 145C(1):45-61

Srebniak M, Boter M, Oudesluijs G, Cohen-Overbeek T, Govaerts L, Diderich K et al (2012) Genomic SNP array as a gold standard for prenatal diagnosis of foetal ultrasound abnormalities. Mol Cytogenet 5:14

Srinivasan A, Bianchi D, Huang H, Sehnert A, Rava R (2013) Noninvasive detection of fetal subchromosome abnormalities via deep sequencing of maternal plasma. Am J Hum Genet 92:167-176

Stankiewicz P, Beaudet A (2007) Use of array CGH in the evaluation of dysmorphology, malformations, developmental delay, and idiopathic mental retardation. Curr Opin Genet Dev 17:182-192

Tyreman M, Abbott K, Willatt L, Nash R, Lees C, Whittaker J et al (2009) High resolution array analysis: diagnosing pregnancies with abnormal ultrasound findings. J Med Genet 46:531-541

UK NSC (2007) National Screening Committee and NHS antenatal and newborn screening programmes. Antenatal screening-working standards for down's syndrome screening 2007. National down's syndrome screening programme for England

Van den Veyver I, Patel A, Shaw C, Pursley A, Kang S, Simovich M et al (2009) Clinical use of array comparative genomic hybridization (aCGH) for prenatal diagnosis in 300 cases. Prenat Diagn 29:29-39

Veltman J, de Vries B (2006) Diagnostic genome profiling: unbiased whole genome or targeted analysis? J Mol Diagn 8: 534-537

Vermeesch JR, Fiegler H, de Leeuw N, Szuhai K, Schoumans J, Ciccone $\mathrm{R}$ et al (2007) Guidelines for molecular karyotyping in constitutional genetic diagnosis. Eur J Hum Genet 15:1105-1114

Vetro A, Bouman K, Hastings R, McMullan D, Vermeesch JR, Miller $\mathrm{K}$ et al (2012) The introduction of arrays in prenatal diagnosis: a special challenge. Hum Mutat 33:923-929 
Wapner R, Driscoll D, Simpson J (2012a) Integration of microarray technology into prenatal diagnosis: counselling issues generated during the NICHD clinical trial. Prenat Diagn 32:396-400

Wapner R, Martin C, Levy B, Ballif B, Eng C, Zachary J et al (2012b) Chromosomal microarray versus karyotyping for prenatal diagnosis. N Engl J Med 367:2175-2184

Wilfond B, Nolan K (1993) National policy development for the clinical application of genetic diagnostic technologies. Lessons from cystic fibrosis. JAMA 270:2948-2954
Wilson J, Jungner G (1968) Principles and practice of screening for disease. World Health Organisation, Geneve

Zuffardi O, Vetro A, Brady P, Vermeesch J (2011) Array technology in prenatal diagnosis. Semin Fetal Neonatal Med 16:94-98 